\title{
Nutrient-Sensing Hypothalamic TXNIP Links Nutrient Excess to Energy Imbalance in Mice
}

\author{
Clémence Blouet and Gary J. Schwartz \\ Departments of Medicine and Neuroscience, Albert Einstein College of Medicine, Bronx, New York 10461
}

\begin{abstract}
Nutrient excess in obesity and diabetes is emerging as a common putative cause for multiple deleterious effects across diverse cell types, responsible for a variety of metabolic dysfunctions. The hypothalamus is acknowledged as an important regulator of whole-body energy homeostasis, through both detection of nutrient availability and coordination of effectors that determine nutrient intake and utilization, thus preventing cellular and whole-body nutrient excess. However, the mechanisms underlying hypothalamic nutrient detection and its impact on peripheral nutrient utilization remain poorly understood. Recent data suggest a role for thioredoxininteracting protein (TXNIP) as a molecular nutrient sensor important in the regulation of energy metabolism, but the role of hypothalamic TXNIP in the regulation of energy balance has not been evaluated. Here we show in mice that TXNIP is expressed in nutrient-sensing neurons of the mediobasal hypothalamus, responds to hormonal and nutrient signals, and regulates adipose tissue metabolism, fuel partitioning, and glucose homeostasis. Hypothalamic expression of TXNIP is induced by acute nutrient excess and in mouse models of obesity and diabetes, and downregulation of mediobasal hypothalamic TXNIP expression prevents diet-induced obesity and insulin resistance. Thus, mediobasal hypothalamic TXNIP plays a critical role in nutrient sensing and the regulation of fuel utilization.
\end{abstract}

\section{Introduction}

The hypothalamus is a major center of convergence and integration of multiple nutrient-related signals important in the regulation of energy homeostasis. In response to nutrients, and adiposity and gut hormones, subsets of specialized nutrient-sensitive hypothalamic neurons engage a complex set of neurochemical and neurophysiological responses to regulate behavioral and metabolic effectors of energy balance (Morton et al., 2006), glycemic control (Parton et al., 2007), and lipid metabolism (Nogueiras et al., 2007; Buettner et al., 2008). These hypothalamic neurons are critical in determining whole-body nutrient availability, utilization, and partitioning, thus limiting nutrient excess, a common feature of obesity and diabetes. However, our current understanding of the mechanisms underlying hypothalamic nutrient detection and its impacts on peripheral metabolism remains incomplete.

Thioredoxin-interacting protein (TXNIP) is an endogenous negative regulator of thioredoxin (Nishiyama et al., 1999), a major ubiquitously expressed thiol-reducing non-enzymatic antioxidant. Hcb-19 mice, bearing a naturally occurring loss-of-

Received Dec. 9, 2010; revised Jan. 22, 2011; accepted Feb. 16, 2011.

This work was supported by National Institutes of Health Grants DK 047208, DK026687 (New York Obesity Research (enter), and DK 020541 (Albert Einstein College of Medicine Diabetes Research and Training (enter) and the Skirball Institute for Nutrient Sensing. C.B. is supported by a grant from the American Heart Association. We thank R. T. Lee and W. Chutkow from Brigham and Women's Hospital at Harvard Medical School for providing TXNIP lentivirus plasmids and TXNIP ${ }^{\mathrm{f} / \text { /f }}$ mice and A. Shalev from the University of Wisconsin for providing us with Hcb19 and $\mathrm{C} 3 \mathrm{H}$ mice.

The authors declare no competing financial interests.

Correspondence should be addressed to Dr. Gary J. Schwartz, Departments of Medicine and Neuroscience, Albert Einstein College of Medicine, 1300 Morris Park Avenue, Golding 501, Bronx, NY 10461. E-mail: gary.schwartz@einstein.yu.edu.

DOI:10.1523/JNEUROSCI.6498-10.2011

Copyright $\odot 2011$ the authors $\quad 0270-6474 / 11 / 316019-09 \$ 15.00 / 0$ function mutation of the TXNIP gene, were first described as a model for familial combined hyperlipidemia, sharing multiple features of impaired lipid metabolism with this human pathology (Bodnar et al., 2002; Hui et al., 2004; Sheth et al., 2005). Both HcB-19 and engineered TXNIP-null mice are also hypoglycemic, hyperinsulinemic, ketotic, and exhibit a $40 \%$ increase in their fat to muscle ratio, suggesting a role for TXNIP in glucose homeostasis, nutrient utilization, and partitioning (Sheth et al., 2005; Chen et al., 2008; Hui et al., 2008), but the mechanisms underlying this phenotype remain elusive. Interestingly, thioredoxin is densely expressed in selective regions of the hypothalamus and brainstem critically involved in metabolic control (Lippoldt et al., 1995), suggesting the possibility that neuronal TXNIP in these regions may play a heretofore unexplored role in the regulation of energy balance. Consequently, in this study, we assessed the role of mediobasal hypothalamic TXNIP in the regulation of energy balance and in the response to nutrient excess.

\section{Materials and Methods}

Animals. All studies were performed on male mice of 10 weeks of age at the beginning of the experiments, unless otherwise stated, and housed as described previously (Blouet et al., 2009). Male C57BL/6 and NONc$\mathrm{NZO10/LtJ} \mathrm{mice} \mathrm{were} \mathrm{obtained} \mathrm{from} \mathrm{The} \mathrm{Jackson} \mathrm{Laboratory.} \mathrm{C3H} \mathrm{con-}$ genic TXNIP-deficient Hcb19 and control C3H/DiSnA (C3H) mice (Hui et al., 2004) were obtained from Dr. A. Shalev (University of Wisconsin, Madison, WI). All experimental protocols were approved by the Institute for Animal Studies of the Albert Einstein College of Medicine.

Lentiviral tools. Human TXNIP (hTXNIP), C247S hTXNIP, and enhanced green fluorescent protein (EGFP) plasmids (a gift from Prof. R. T. Lee, Brigham and Women's Hospital at Harvard Medical School) were packaged into lentiviruses by System Bioscience. LacZ lentivirus was purchased from Genecure. Functional validation of lentiviral tools was performed in vitro on N41 embryonic hypothalamic cells (Cellutions 
Biosystems) and plated in DMEM with $4500 \mathrm{mg} / \mathrm{L}$ glucose $24 \mathrm{~h}$ before transduction with hTXNIP, LacZ, TXNIP short hairpin RNA (shRNA), or control shRNA lentivirus. Forty-eight hours later, cells were harvested and processed for TXNIP expression as described below.

Stereotaxic surgery and viral injections. Stereotaxic surgery to target the mediobasal hypothalamus (MBH) was performed under ketamine/xylazine anesthesia as described previously (Blouet et al., 2009). Mice were injected with lentivirus particles $\left(1 \times 10^{9} \mathrm{pfu} / \mathrm{ml}, 500 \mathrm{nl} /\right.$ side over a 10 min period, injection rate of $50 \mathrm{nl} / \mathrm{min}$ ). At the end of the experiment, all mice were killed by decapitation, and hypothalamic nuclei were systematically dissected as described previously (Blouet et al., 2009) to perform Western blot or reverse transcription (RT)-PCR analyses and confirm successful TXNIP overexpression or downregulation.

Metabolic phenotyping. One week before lentivirus injection, mice were adapted to individual feeding chambers (Med Associates) equipped with $20 \mathrm{mg}$ pellet dispensers and fed ad libitum with a standard chow diet or a high-fat diet (Bioserv precision pellets F05524, $15.8 \mathrm{~kJ} / \mathrm{g}$ and Bioserv precision pellets F06294, $22.8 \mathrm{~kJ} / \mathrm{g}$, respectively). Food intake was monitored continuously from $4 \mathrm{~d}$ before to $20-25 \mathrm{~d}$ after virus administration, and body weight (BW) was assessed daily. Meal patterns were determined as described previously (Azzara et al., 2002). Body composition was determined by magnetic resonance spectroscopy using an ECHO MRS instrument (Echo Medical Systems). To determine energy expenditure, mice were adapted to individual metabolic chambers. Metabolic measurements (oxygen consumption, carbon dioxide production, food intake, and locomotor activity) were obtained continuously using a CLAMS (Columbus Instruments) open-circuit indirect calorimetry system for 7 consecutive days. Glucose tolerance was assessed with a $1 \mathrm{~g} / \mathrm{kg}$ BW oral glucose challenge after a $6 \mathrm{~h}$ daytime fast with tail blood sampling. Insulin sensitivity was assessed using a $0.75 \mathrm{U}$ intraperitoneal insulin challenge after a $6 \mathrm{~h}$ daytime fast with tail blood sampling.

CL316243 challenge. After blood collection for basal measurements, mice received an intraperitoneal injection of $1 \mathrm{mg} / \mathrm{kg}$ BW CL316243 (5- [(2R)-2[[(2R)-2-(3-chlorophenyl)-2-hydroxyethyl $]$ amino]propyl]-1,3-benzodioxole-2,2-dicarboxylic acid disodium salt) (Sigma), a $\beta 3$ adrenergic agonist. Blood was collected $15 \mathrm{~min}$ later for plasma non-esterified free fatty acid (NEFA) measurement, and plasma NEFA change over that time period was calculated. Brown fat temperature was monitored as described below, over the $60 \mathrm{~min}$ after the CL316243 injection, and brown fat temperature change over that time period was calculated.

Brown fat temperature monitoring. Mice were implanted with radiofrequency impedance temperature probes (MiniMitter) under the intrascapular brown fat pad, under isoflurane anesthesia, and allowed a 1 week recovery. Brown fat temperature was recorded using MiniMitter ER4000 receivers. For the cold challenge experiment, mice were exposed for $2 \mathrm{~h}$ to $4^{\circ} \mathrm{C}$, and brown fat temperature was recorded continuously.

Euglycemic hyperinsulinemic clamp. Mice were injected with hTXNIP, C247S hTXNIP, TXNIP shRNA, or the control shRNA lentiviruses into the $\mathrm{MBH} 3$ weeks before vascular surgery was performed. Catheters were placed in the internal jugular vein and the carotid artery, and, 1 week later, insulin euglycemic pancreatic clamp procedures were performed on conscious, freely moving animals. The protocol consisted of a $90 \mathrm{~min}$ tracer equilibration period (0-90 $\mathrm{min}$ ), followed by a $120 \mathrm{~min}$ experimental period (90-210 min). On the day of the experiment, mice were fasted for $4 \mathrm{~h}$ before the beginning of the tracer infusion. At $0 \mathrm{~min}$, a primed, continuous intravenous infusion of $\left[{ }^{3} \mathrm{H}\right]$ glucose $(5 \mu \mathrm{Ci}$ bolus, $0.1 \mu \mathrm{Ci} / \mathrm{min}$; PerkinElmer Life and Analytical Sciences) was begun and maintained throughout the study. Ninety minutes after the beginning of the tracer infusion, a continuous infusion of insulin (2.5 $\mathrm{mU} \cdot \mathrm{kg}^{-1} \cdot \mathrm{min}^{-1}$ for hTXNIP and C247S TXNIP mice, 2 $\mathrm{mU} \cdot \mathrm{kg}^{-1} \cdot \mathrm{min}^{-1}$ for TXNIP shRNA and control shRNA mice; Humulin R; Eli Lilly) was started and tracer infusion was increased to $0.3 \mu \mathrm{Ci} /$ min to minimize changes in specific activity from the equilibration period. At $100 \mathrm{~min}$, a variable infusion of a $45 \%$ glucose solution, which was adjusted periodically to clamp the plasma glucose concentration at the basal level measured in the first part of the procedure, was begun. Samples for determination of $\left[{ }^{3} \mathrm{H}\right]$ glucose-specific activity were obtained at 70, 80, and $90 \mathrm{~min}$ for the basal period and then at 170, 180, 190, 200, and $210 \mathrm{~min}$ for the clamp period. From 70 to $210 \mathrm{~min}$, plasma
Table 1. Primer sequences

\begin{tabular}{lll}
\hline Actin & Forward & CTGGAGAAGAGCTATGAGCTGCCT \\
Actin & Reverse & CTCCTGCTTGCTGATCCACATCTG \\
ATGL & Forward & GGAGACCAAGTGGACATCTCA \\
ATGL & Reverse & AATAATGTTGGCACCTGCTTCA \\
Caveolin & Forward & ACCTCTCTGGACTGGCAGAA \\
Caveolin & Reverse & TCCCTGGAGGTTCACTCATC \\
F4/80 & Forward & CTTTGGCTATGGGCTTCAGTC \\
F4/80 & Reverse & GCAAGGAGGACAGAGTTTATCGTG \\
HSL & Forward & GCTTGGTTCAACTGGAGAGC \\
HSL & Reverse & GCCTAGTGCCTCTGGTCTG \\
PGC1 $\alpha$ & Forward & TAGGCCCAGGTACGACAGC \\
PGC1 $\alpha$ & Reverse & TGCATTCCTCAATTTCACCA \\
Plin & Forward & GATCGCCTCTGAACTGAAGG \\
Plin & Reverse & CTTCTCGATGCTTCCCAGAG \\
mTXNIP & Forward & GTGCAGAAGATCAGACCATCC \\
mTXNIP & Reverse & AGCCAGGGACACTGACGTA \\
UCP1 & Forward & GCCTTCAGATCCAAGGTGA \\
UCP1 & Reverse & CGAGATCTTGTTCCAAAG \\
hTXNIP & Forward & TTCGGGTCAGAAGATCAGG \\
hTXNIP & Reverse & GGATCCAGGAACGCTAACAT \\
\hline
\end{tabular}

glucose levels were determined every $10 \mathrm{~min}$ using a GM7 Micro-Stat (Analox Instruments). Plasma for the determination of insulin levels were collected at 90, 170, and $210 \mathrm{~min}$. Erythrocytes collected from each blood sample were saline washed and reinfused into the mice to prevent a fall in hematocrit. Plasma $\left[{ }^{3} \mathrm{H}\right]$ glucose radioactivity was determined as described previously (Ross et al., 2010). Whole-body glucose appearance $\left(R_{\mathrm{a}}\right)$ and disappearance $\left(R_{\mathrm{d}}\right)$ were determined using Steele non-steadystate equations (Steele et al., 1956). Endogenous glucose production (endo $R_{\mathrm{a}}$ ) was determined by subtracting the glucose infusion rate from total glucose appearance.

MBH leptin, insulin, and glucose infusions. Overnight food-deprived mice equipped with bilateral cannulae targeting the $\mathrm{MBH}$ received an $\mathrm{MBH}$ injection of artificial CSF ( $\mathrm{aCSF}$ ), leptin (recombinant mouse leptin, $150 \mathrm{ng}$ in $150 \mathrm{nl} /$ side over $5 \mathrm{~min}$; R \& D Systems), insulin (human insulin, $250 \mu \mathrm{U}$ in $100 \mathrm{nl} /$ side over $5 \mathrm{~min}$; Actrapid), or glucose (1 $\mu \mathrm{l}$ of $20 \%$ glucose over $4 \mathrm{~h}$; Sigma), and MBH extracts were collected $30 \mathrm{~min}$ later for signaling studies or $4 \mathrm{~h}$ after the beginning of the infusion to assess TXNIP expression. Hypothalamic leptin sensitivity was assessed by measuring $24 \mathrm{~h}$ food intake and body weight change after a local leptin injection in the $\mathrm{MBH}$ ( $150 \mathrm{ng}$ in $150 \mathrm{nl} /$ side) after a $6 \mathrm{~h}$ fast $1 \mathrm{~h}$ before the onset of the dark.

Analytical procedures. Blood glucose levels were determined using a Glucometer (Precision Xtra; MediSense), plasma insulin levels using ELISA (Linco Mouse Insulin kit), and plasma triglycerides, NEFA, and $\beta$-hydroxybutyrate using a colorimetric assay (Sigma, Wako, and Biovision, respectively). Fasted levels were assessed after an overnight food deprivation and refed levels after a $4 \mathrm{~h}$ refeeding period. For NEFA and triglycerides analysis, blood was collected on para-oxon ethyl (lipase inhibitor) and EDTA-coated tubes, and for insulin and $\beta$-hydroxybutyrate, blood was collected on EDTA-coated tubes.

Streptozotocin treatment. Mice received a single intraperitoneal injection of streptozotocin $(0.175 \mathrm{~g} / \mathrm{kg}$ body weight in $0.1 \mathrm{~mol} / \mathrm{L}$ citrate; Promega). Blood glucose levels were measured daily, and animals were killed for TXNIP expression experiments $4 \mathrm{~d}$ later.

Real-time PCR. RNA extraction, preparation, and real-time PCR experiments were performed as described previously (Blouet et al., 2008). Quantitative real-time RT-PCR was run using LC-Fast Start DNA SYBR Green I chemistry (Roche Diagnostics) on a LightCycler 2.0 platform (Roche Diagnostics). For hTXNIP measurements, quantitative real-time RT-PCR was run using FastStart Universal Probe Master on a 480 LightCycler (Roche Diagnostics). Forward and reverse primer pairs were as listed (Table 1). Relative quantification of each transcript compared with $\beta$-actin was determined as reported previously (Blouet et al., 2008).

Immunoblot analysis. White adipose tissue was homogenized in 50 mM Tris, 1 mм EGTA, 1 mm EDTA, $50 \mathrm{~mm}$ sodium fluoride, $10 \mathrm{~mm}$ $\beta$-glycerophosphate, $20 \mathrm{~mm}$ sodium pyrophosphate, $2 \mathrm{~mm}$ orthovana- 
date, 2 mm PMSF, and Complete phosphatase inhibitor cocktail (Roche), without Triton X-100. After low-speed centrifugation $\left(2600 \times g\right.$ at $\left.4^{\circ} \mathrm{C}\right)$, the fat layer was removed and Triton X-100 was added to a final concentration of $1 \%$. Hypothalamic wedges and brown adipose tissue were directly homogenized in the Triton X-100-containing buffer. After incubation at $4^{\circ} \mathrm{C}$ for $30 \mathrm{~min}$, the extracts were cleared by centrifugation at $20,000 \times g$ for $15 \mathrm{~min}$. Protein concentration was measured with a BCA protein quantification kit (Pierce Biotechnology). Protein extracts were run on Criterion gels (Bio-Rad) and blotted onto nitrocellulose membranes (Millipore). After blocking for $1 \mathrm{~h}$ at room temperature, immunoblots were incubated overnight at $4^{\circ} \mathrm{C}$ in primary antibodies against phospho-STAT3 (Tyr705), STAT3, phospho-Akt (Ser 473), Akt, phospho$\alpha$-AMP-activated protein kinase (AMPk) (Thr 172), $\alpha$ AMPk, phosphohormone-sensitive lipase (HSL) (Ser563), HSL, phosphor-acetyl-CoA carboxylase (ACC) (Ser79), ACC (Cell Signaling Technology), TXNIP (MBL International), thioredoxin (Abcam), or $\beta$-actin (Santa Cruz Biotechnology). Blots were then incubated for $1 \mathrm{~h}$ in fluorescent [Alexa Fluor 680-conjugated anti-mouse IgG (Invitrogen) or IR Dye 800conjugated goat anti-rabbit IgG (Rockland Immunochemicals)] or HRP-linked (anti-rabbit or anti-mouse HRP-linked IgG; Cell Signaling Technology) secondary antibodies, and proteins were detected using either the fluorescence-based Odyssey Infrared Imaging System (LI-COR Biosciences) or enhanced chemiluminescence (ECL Plus; GE Healthcare). Quantification was performed as described previously (Blouet et al., 2009).

Thioredoxin activity assay. Thioredoxin "insulin-reducing assay" was performed as described (Holmgren and Björnstedt, 1995), with some modifications. $\mathrm{MBH}$ wedges were homogenized in $20 \mathrm{~mm}$ HEPES, $\mathrm{pH}$ 7.9, $100 \mathrm{~mm} \mathrm{KCl,} 300 \mathrm{~mm} \mathrm{NaCl}, 10$ mм EDTA, 0.1\% Triton X-100, 2 mм sodium orthovanadate, and anti-protease cocktail (Roche). One hundred micrograms of protein in $102 \mu \mathrm{l}$ were incubated for $15 \mathrm{~min}$ at $37^{\circ} \mathrm{C}$ with $3 \mu \mathrm{l}$ of DTT activation buffer (50 mм HEPES, pH 7.6, 1 mм EDTA, $1 \mathrm{mg} / \mathrm{ml} \mathrm{BSA}$, and $2 \mathrm{~mm}$ DTT). Sixty microliters of reaction mixture (200 $\mu \mathrm{l}$ of $1 \mathrm{~m}$ HEPES, pH 7.6, $40 \mu \mathrm{l}$ of $0.2 \mathrm{~m}$ EDTA, $40 \mu \mathrm{l}$ of NADPH at 40 $\mathrm{mg} / \mathrm{ml}$, and $500 \mu \mathrm{l}$ of insulin at $10 \mathrm{mg} / \mathrm{ml}$ ) was then added to each sample. Forty microliters of each sample was then transferred to a 96-well plate, and $0.25 \mathrm{U}$ of thioredoxin reductase or water (negative control) was added, followed by incubation at $37^{\circ} \mathrm{C}$ for $20 \mathrm{~min}$. The reaction was stopped by addition of $187.5 \mu \mathrm{l}$ of stop buffer [ $6 \mathrm{M}$ guanidine $\mathrm{HCl}, 1 \mathrm{~mm}$ $5,5^{\prime}$-dithio-bis(2-nitrobenzoic acid) in $0.2 \mathrm{~m}$ Tris- $\mathrm{HCl}, \mathrm{pH}$ 8]. Absorbance at $412 \mathrm{~nm}$ was read against a thioredoxin standard curve.

Tissue collection for immunostaining and immunostaining. Mice were anesthetized using pentobarbital. Brains were perfused transcardially and processed as described previously (Blouet et al., 2009). Coronal hypothalamic sections of 25-35 $\mu \mathrm{m}$ thickness were prepared on a freezing microtome, and free-floating sections were with $0.3 \%$ hydrogen peroxide for $15 \mathrm{~min}$ and washed three times for $10 \mathrm{~min}$ with PBS before the following treatments. Sections were blocked $2 \mathrm{~h}$ with $5 \%$ normal goat antiserum (NGS) and incubated in TXNIP antiserum (1:500; MBL International) with $0.3 \%$ Triton X-100 and 5\% NGS in PBS for $24 \mathrm{~h}$ with gentle agitation. For light microscopy, sections were then incubated overnight at $4^{\circ} \mathrm{C}$ using biotinylated goat anti-mouse $\operatorname{IgG}(1: 400)$ and then incubated in avidin-biotin-peroxidase complex (Elite Vectastain kit; Vector Laboratories). For immunofluorescence, sections were exposed for $2 \mathrm{~h}$ to cyanine 3 -conjugated goat anti-mouse (1:400; Jackson ImmunoResearch), washed in PBS, floated onto gelatinized slides, and coverslipped with Vectashield (Vector Laboratories). Fluorescence was visualized with the appropriate lasers and emission filters on an LSM 510 NLO multiphoton confocal microscope (Carl Zeiss).

Image analysis. Images of tissue sections were digitized, and areas of interest were outlined based on cellular morphology. Brain regions evaluated were lateral hypothalamus (LH) $(0.7-1.4 \mathrm{~mm}$ caudal, $0.75-1.5 \mathrm{~mm}$ mediolateral, and $4.5-5.5 \mathrm{~mm}$ dorsoventral to bregma), paraventricular hypothalamus $(\mathrm{PVN})(0.7-0.9 \mathrm{~mm}$ caudal, $0-0.5 \mathrm{~mm}$ mediolateral, and $4.5-5 \mathrm{~mm}$ dorsoventral to bregma), arcuate nucleus (1.5-1.9 mm caudal, $0-0.45 \mathrm{~mm}$ mediolateral, and $5.6-6 \mathrm{~mm}$ ventromedial to bregma), and dorsomedial hypothalamus (1.7-1.9 mm caudal, $0-0.7 \mathrm{~mm}$ ventromedial, and 4.9-5.4 mm dorsoventral to bregma), corresponding to the coordinates in the brain atlas of Paxinos and Franklin (2001).
Statistical analysis. All data, presented as means \pm SEM, have been analyzed using GraphPad Prism 5. For all statistical tests, an $\alpha$ risk of 5\% was used. All kinetics were analyzed using a mixed model for repeated measurements. Multiple comparisons were tested with an ANOVA and adjusted with Tukey's post hoc tests. Single comparisons were made using one-tail Student's $t$ tests.

\section{Results}

TXNIP expression in the hypothalamus and nutritional regulation in normal physiology

We first localized TXNIP protein in the mouse brain using an antibody specific for TXNIP (Fig. $1 A, B, D$ ). TXNIP was densely expressed in the arcuate, the ventromedial, the lateral, and the paraventricular nuclei of the hypothalamus (Fig. $1 C$ ). TXNIP was also expressed in the brainstem in the nucleus of the solitary tract, the area postrema, and the dorsal motor nucleus of the vagus. TXNIP was moderately expressed in the hippocampus, central thalamus nuclei, paraventricular thalamus nucleus, medial preoptic area, and cortex, with minimal expression outside these areas. Thus, TXNIP is expressed in hypothalamic nuclei rich in nutrient-sensing neurons and involved in the control of energy homeostasis. To begin to assess the physiological relevance of hypothalamic TXNIP in the regulation of energy homeostasis, we investigated whether acute changes in nutrient availability affect hypothalamic TXNIP expression. In the MBH, there was a significant decrease in both TXNIP mRNA and protein expression in mice refed for $4 \mathrm{~h}$ after a $24 \mathrm{~h}$ fast compared with non-refed controls, whereas nutritional status did not significantly affect TXNIP expression in the paraventricular and lateral nuclei of the hypothalamus (Fig. 1E). Consistently, thioredoxin activity tended to be higher in refed mice compared with fasted controls. We then assessed the effect of the adiposity hormones insulin and leptin, long-term signals of energy availability, on MBH TXNIP expression using MBH parenchymal administration. The volumes used for these injections ( $100-150 \mathrm{nl} /$ side) were sufficiently low to ensure site specificity, as reported previously (Blouet et al., 2009), and did not induce any changes in circulating glucose, leptin, or insulin (data not shown). We found that acute administration of both insulin and leptin decreased MBH TXNIP expression (Fig. $1 F$ ). Thus, in healthy mice, MBH TXNIP expression is suppressed both by signals reflecting acute and long-term energy availability.

\section{MBH TXNIP expression in nutrient excess and metabolic diseases}

TXNIP expression has been shown to be upregulated by high glucose levels in pancreatic $\beta$-cells, and this induction has been implicated in glucotoxic $\beta$-cell loss (Chen et al., 2008). Thus, we explored the effect of nutrient excess, a condition that promotes the onset of metabolic diseases, on MBH TXNIP expression. In mice acutely exposed to hypothalamic glucose excess, achieved through a $4 \mathrm{~h} \mathrm{MBH}$ glucose infusion, we found a $45 \%$ increase in MBH TXNIP protein expression (TXNIP protein expression corrected to actin in the $\mathrm{MBH}: 1.71 \pm 0.20$ vs $2.39 \pm 0.28$ in aCSF vs glucose perfused mice; $p<0.05, n=5$ ), indicating that glucose excess increases MBH TXNIP expression. To extend this finding to pathologic conditions associated with chronic glucose excess, we measured MBH TXNIP expression in mouse models of obesity and/or diabetes with overt hyperglycemia. In 3-month-old NONcNZO10/LtJ mice, a polygenic model of obesity and type 2 diabetes with adult onset diet-induced hyperglycemia and obesity, MBH TXNIP expression was dramatically increased in refed mice, and MBH TXNIP nutritional regulation was reversed (Fig. 


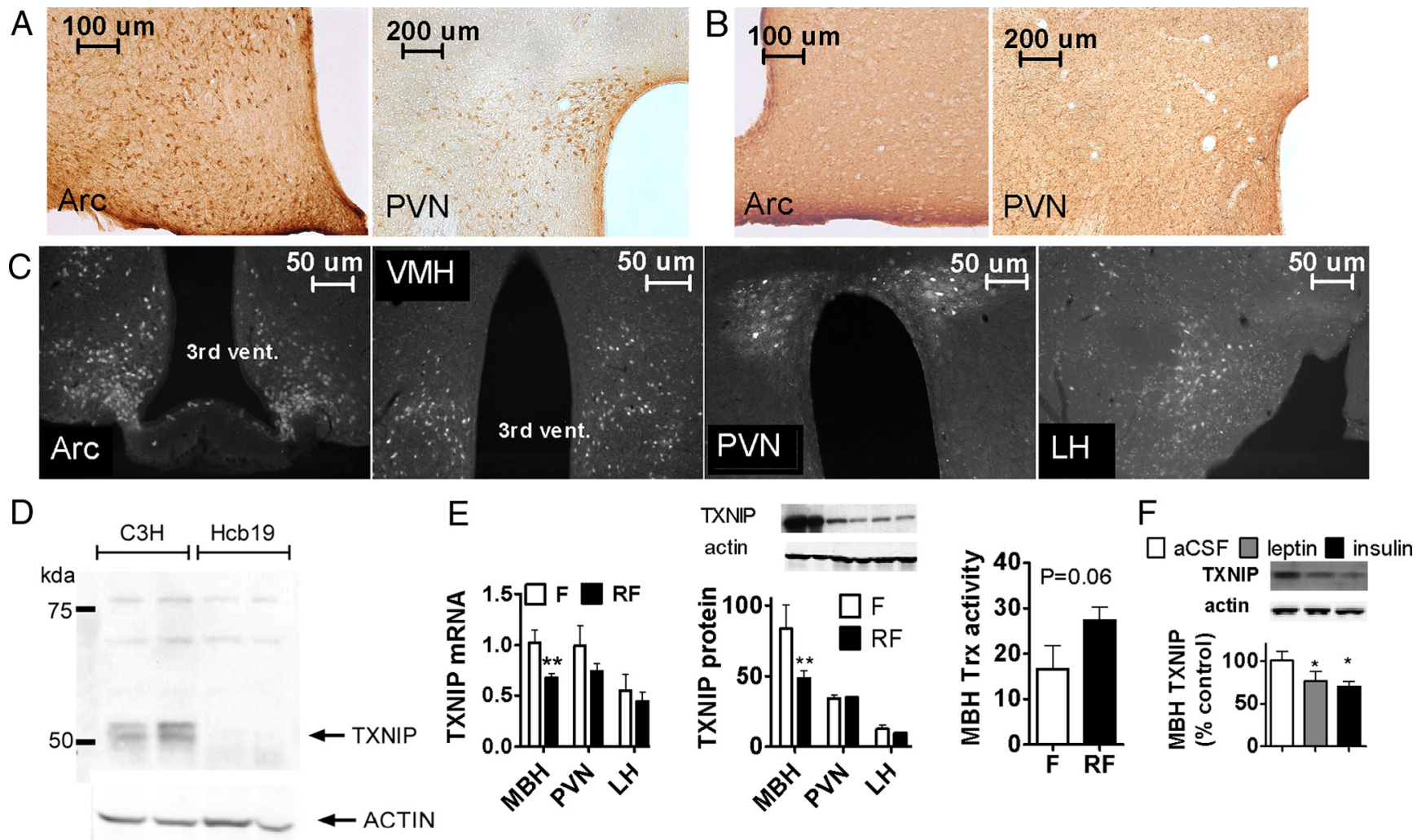

Figure 1. TXNIP is expressed in the hypothalamus and is suppressed by nutritional and hormonal signals of energy availability. Immunohistochemistry showing TXNIP in the MBH and the PVN of a C3H wild-type control $(\boldsymbol{A})$ and a Hcb-19 TXNIP-deficient mouse (B). $\boldsymbol{C}$, Immunohistochemistry showing TXNIP expression in the arcuate (Arc), the ventromedial (VMH), the PVN, and the LH nuclei of the hypothalamus in a C57BL/6 mouse. D, Western blot analyses of MBH TXNIP expression in $\mathrm{C} 3 \mathrm{H}$ and Hcb-19 mice. $\boldsymbol{E}$, TXNIP mRNA and protein expression corrected to actin, and thioredoxin activity in the MBH, PVN, and/or LH of $24 \mathrm{~h}$ fasted (F) and $4 \mathrm{~h}$ refed (RF) mice $(n=4-6)$. F, MBH TXNIP protein expression corrected to actin after an acute intra-MBH infusion of aCSF, leptin, or insulin $(n=5)$. All data are means \pm SEM. ${ }^{*} p<0.05,{ }^{* *} p<0.01$ versus controls.
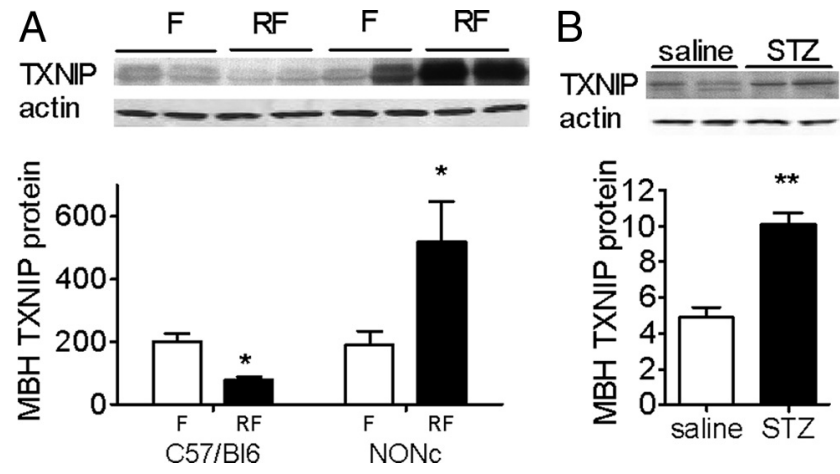

Figure 2. MBH TXNIP expression in mouse models of diabetes. MBH TXNIP protein expression corrected to actin in $24 \mathrm{~h}$ fasted (F) and $4 \mathrm{~h}$ refed (RF) NONcNZ10/LtJ mice (NONc; $A$ ) and streptozotocin (STZ)-treated mice (B). All data are means \pm SEM. ${ }^{*} p<0.05,{ }^{* *} p<0.01$, ${ }^{* * *} p<0.001$ versus controls.

$2 A)$. In streptozotocin-treated mice, a pharmacological model of pancreatic failure-induced hyperglycemia, we found a 2.5 -fold increase in MBH TXNIP expression (Fig. $2 B$ ). Together, these data indicate that, in both acute and chronic conditions of hyperglycemia, TXNIP expression in the MBH is increased and TXNIP nutritional regulation is disrupted.

\section{Metabolic phenotype of mice overexpressing TXNIP in the $\mathrm{MBH}$}

To determine the specific role of MBH TXNIP in the regulation of energy homeostasis and assess a putative role for increased
MBH TXNIP expression in the pathophysiology of metabolic dysfunction associated with nutrient excess, we overexpressed TXNIP in the mouse MBH: we stereotaxically targeted the $\mathrm{MBH}$ with lentivectors expressing hTXNIP, a mutant of hTXNIP [C247S hTXNIP, mutation of a single cysteine, Cys-247, that abolishes the ability of TXNIP to bind thioredoxin and inhibit thioredoxin activity (Patwari et al., 2006)], or LacZ and evaluated the effects of these manipulations on multiple behavioral and metabolic effectors of energy balance. Lentivirus functional validity was verified in both N41 hypothalamic cells (data not shown) and $\mathrm{MBH}$ extracts from injected mice. $\mathrm{MBH}$ infection with the hTXNIP lentivirus led to a twofold increase in total TXNIP protein expression in the $\mathrm{MBH}$, without altering TXNIP expression in the PVN or the LH (Fig. 3A), and induced a twofold decrease in thioredoxin activity in the $\mathrm{MBH}(99.8 \pm 8.9$ vs $50.8 \pm$ 6.1 expressed as percentage of controls in C247S hTXNIP and hTXNIP mice, respectively; $p<0.05)$. Consistently, this decrease in thioredoxin activity promoted an impairment in intracellular redox status, as evidenced by significant increased levels of oxidized glutathione in hTXNIP mice relative to controls $(0.86 \pm$ 0.03 vs $1.18 \pm 0.05 \mu \mathrm{mol} / \mathrm{mg}$ protein in hTXNIP and C247S hTXNIP mice, respectively; $p<0.05$ ).

Although MBH TXNIP overexpression did not significantly affect food intake, body weight gain, or body composition when mice were maintained on a normal chow diet (data not shown), under high-fat feeding, TXNIP overexpression in the MBH increased body weight gain and adiposity compared with expression of both C247S hTXNIP and LacZ control vectors (Fig. 3B). These changes occurred in the absence of any effect on feeding 
A
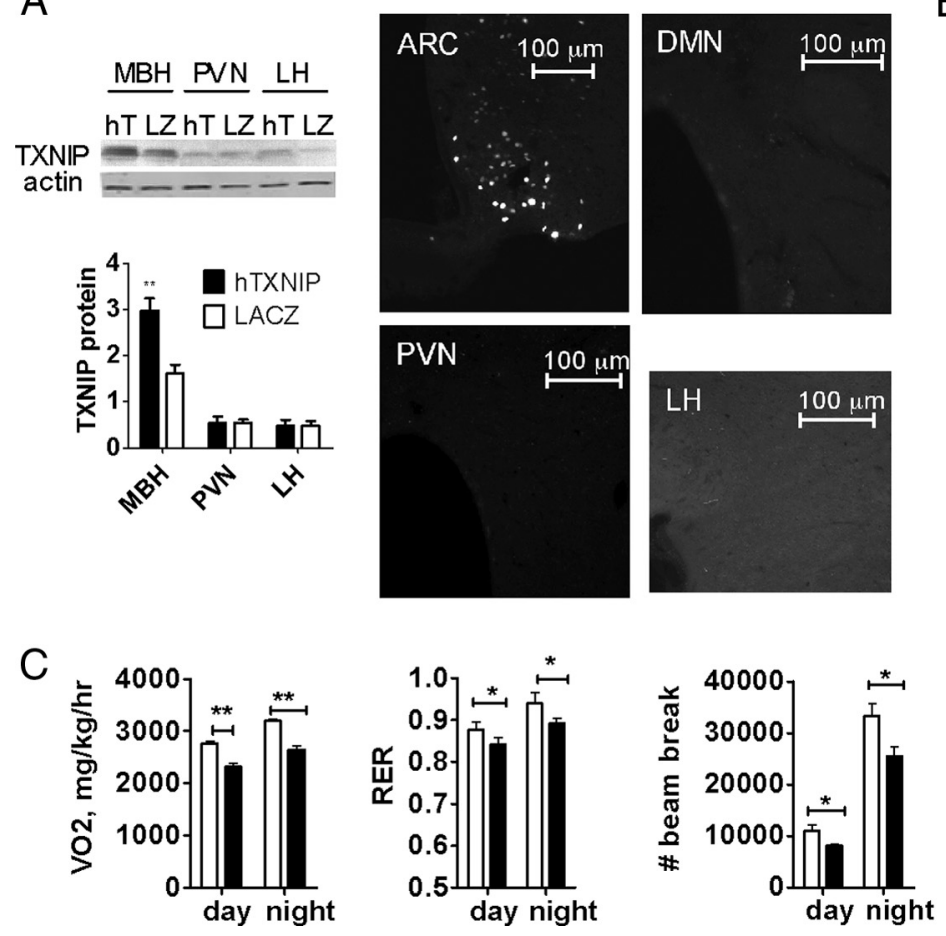

$\mathrm{B}$

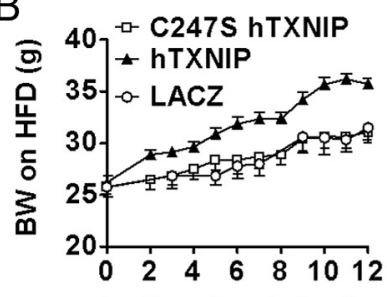

wk after virus injection
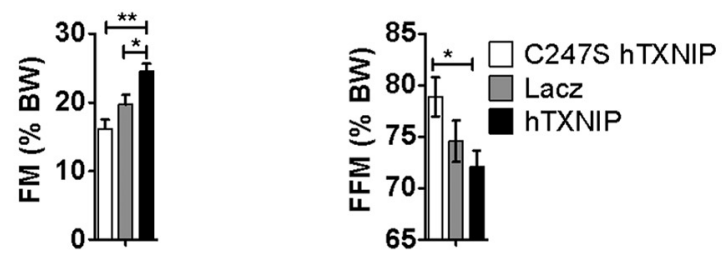

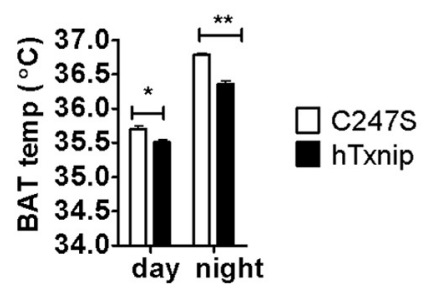

Figure 3. MBH TXNIP overexpression increases body weight and body fat and decreases energy expenditure. $A$, TXNIP protein expression corrected to actin in the MBH, PVN, and LH of mice infected with hTXNIP (hT) or LacZ (LZ) lentivirus $(n=4)$, and viral infection spread (as shown by EGFP immunofluorescence) after MBH stereotaxic infection with an EGFP lentivirus. Body weight, daily food intake, fat mass (FM), and fat free mass (FFM) $(n=6-10)(B)$ and oxygen consumption, respiratory exchange ratio, total spontaneous locomotor, and brown fat temperature $(n=4)(\boldsymbol{C})$ in mice fed a high-fat diet after MBH injection of C247S hTXNIP, LacZ, or hTXNIP lentivirus. All data are means \pm SEM. ${ }^{*} p<0.05,{ }^{* *} p<0.01$ versus controls. ARC, Arcuate nucleus; DMN, dorsomedial hypothalamus; HFD, high-fat diet; RER, respiratory exchange ratio; BAT, brown adipose tissue.
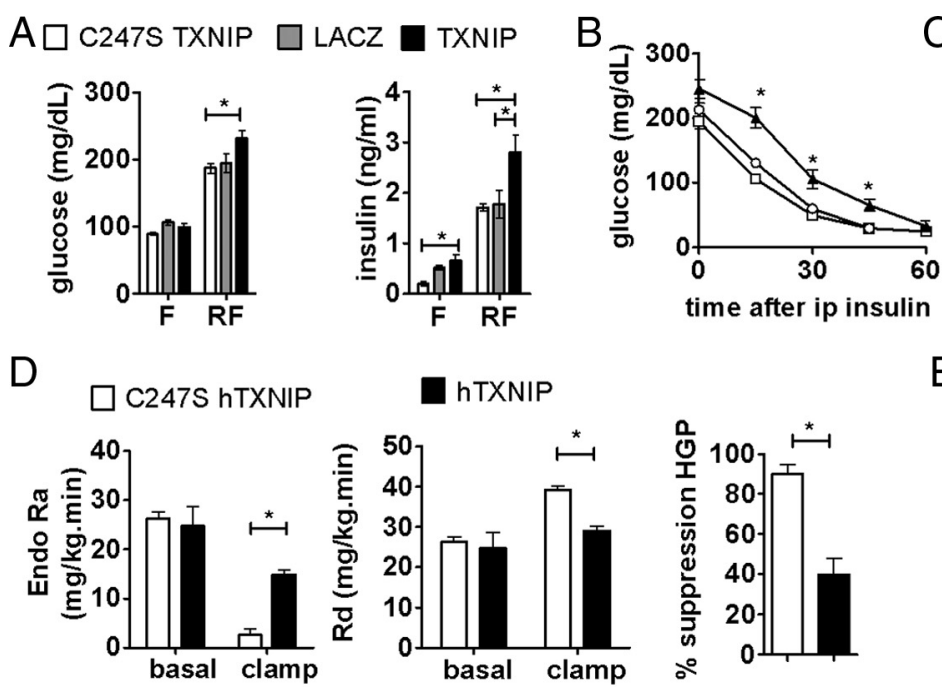

口TXNIP

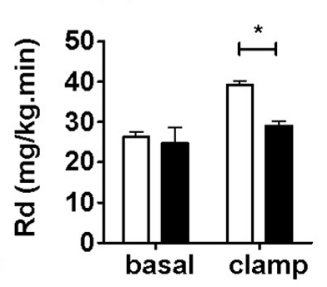

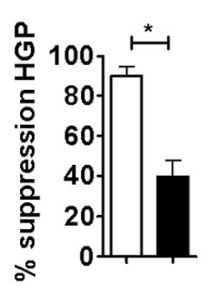

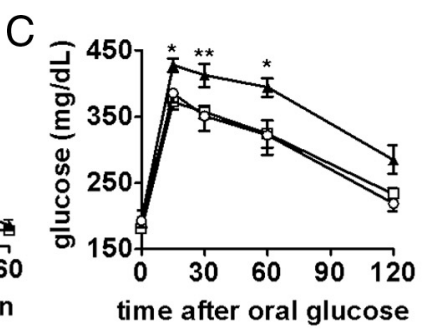

$E$

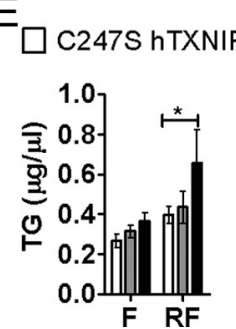

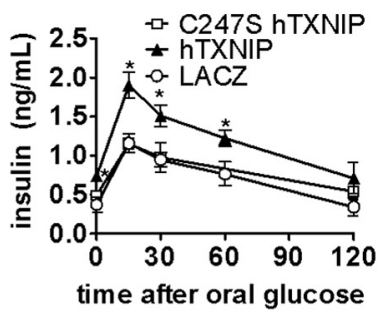

TXNIP
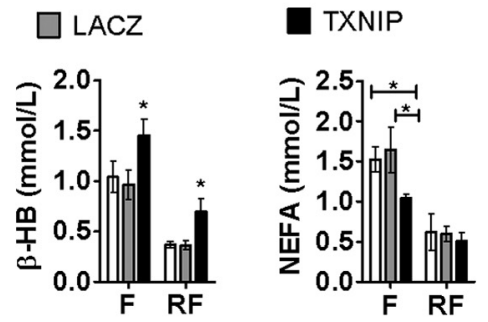

Figure 4. MBH TXNIP overexpression impairs glycemic control and nutrient utilization. Mice were injected with the C247S hTXNIP, LacZ, or hTXNIP lentivirus into the MBH, fed a high-fat diet after the viral injections, and studied in the $24 \mathrm{~h}$ fasted (RF) or $3 \mathrm{~h}$ fed (F) state between 4 and 6 weeks after the viral injection. Blood glucose and plasma insulin ( $n=10)(\boldsymbol{A})$, blood glucose during an intraperitoneal insulin sensitivity test $(n=10)(\boldsymbol{B})$, blood glucose and plasma insulin during an oral glucose tolerance test $(n=10)(\boldsymbol{C})$, endo $R_{\mathrm{a}}, R_{\mathrm{d}}$, and percentage suppression of hepatic glucose production (HGP) during the basal and hyperinsulinemic (clamp) period of a euglycemic clamp $(n=4-5)(\boldsymbol{D})$, and plasma triglycerides (TG), plasma $\beta$-hydroxybutyrate ( $\beta$-HB), and plasma non-esterified free fatty acids $(n=10)(\boldsymbol{E})$. All data are means \pm SEM. ${ }^{*} p<0.05,{ }^{* *} p<0.01$ versus controls.

behavior (Fig. 3B). Oxygen consumption, respiratory quotient, physical activity, and brown fat temperature were decreased in $\mathrm{MBH}$ hTXNIP-expressing mice compared with C247Sexpressing controls (Fig. 3C), suggesting that lower energy expenditure in MBH hTXNIP-expressing mice accounted for their higher rate of body weight gain. MBH TXNIP overexpression in animals maintained on a high-fat diet also led to postprandial hyperglycemia, fasting and postprandial hyperinsulinemia, impaired glycemic response to intraperitoneal insulin, and oral glucose intolerance (Fig. $4 A-C$ ). Clamp studies revealed both a higher hepatic glucose production and a lower peripheral glucose uptake under euglycemic hyperinsulinemic conditions in hTXNIP expressing mice compared with controls (Fig. 4D). Last, overexpression of TXNIP in the MBH resulted in hypertriglycer- 
Table 2. Baseline characteristics of mice injected with the C247S hTXNIP and hTXNIP lentivectors (original experiment) and mice injected with the hTXNIP lentivector and energy restricted or fed ad libitum 3 weeks after viral injections

\begin{tabular}{llll}
\hline C247S hTXNIP hTXNIP & hTXNIP & restricted & hTXNIP ad libitum
\end{tabular}

\begin{tabular}{lrrrr}
\hline Body weight $(\mathrm{g})$ & $25.13 \pm 0.94$ & $28.10 \pm 0.42^{*}$ & $24.82 \pm 0.66$ & $27.14 \pm 0.70^{* *}$ \\
BW gain after injection & $1.27 \pm 0.24$ & $3.40 \pm 0.77^{*}$ & $1.23 \pm 0.24$ & $3.36 \pm 0.55^{* *}$ \\
Fat mass (\%BW) & $15.87 \pm 0.97$ & $22.35 \pm 0.26^{*}$ & $15.12 \pm 1.28$ & $21.99 \pm 1.54^{* *}$ \\
Fat-free mass (\%BW) & $78.69 \pm 1.11$ & $72.41 \pm 0.58^{*}$ & $80.58 \pm 1.34$ & $73.95 \pm 1.47^{* *}$ \\
Fasting glucose $(\mathrm{mg} / \mathrm{dl})$ & $181.14 \pm 4.72$ & $196.60 \pm 12.68$ & $126.20 \pm 2.69^{*}$ & $185.00 \pm 14.32^{* *}$ \\
Fasting insulin $(\mathrm{ng} / \mathrm{ml})$ & $0.50 \pm 0.05$ & $0.68 \pm 0.05^{*}$ & $0.45 \pm 0.10$ & $0.61 \pm 0.09$ \\
\hline${ }^{*}<<0.05$ versus (247S hTXNIP mice; * ${ }^{*}<0.05$ versus hTXNIP restricted mice.
\end{tabular}
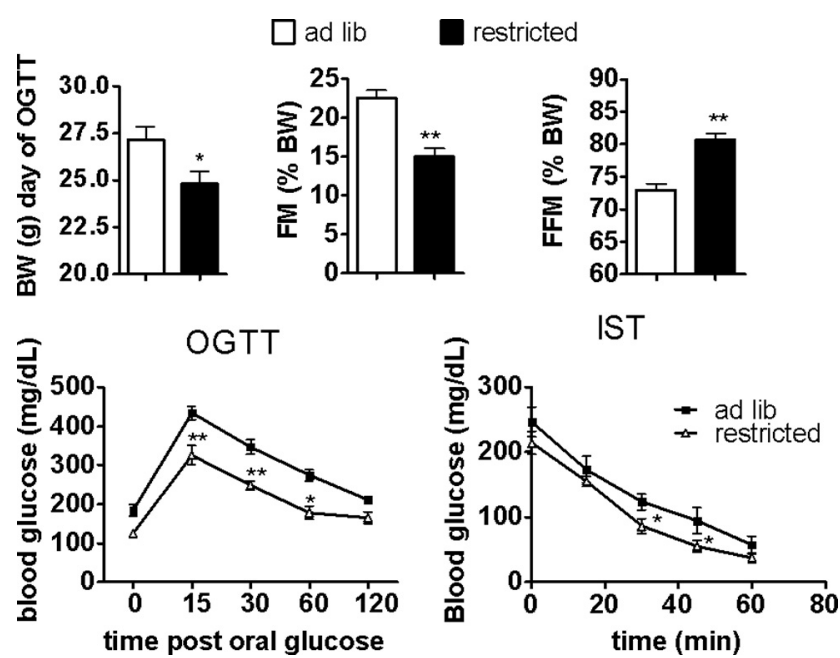

Figure 5. Increased adiposity during MBH TXNIP overexpression contributes to the impairment in glycemic control. Body weight, fat mass (FM), fat free mass (FFM), blood glucose during an oral glucose tolerance test (OGTT), and an intraperitoneal insulin sensitivity test (IST) in hTXNIP-expressing mice fed ad libitum or restricted to match the body weight of C247S hTXNIPexpressing controls for 4 weeks. All data are means $\pm \mathrm{SEM} ; n=6 .{ }^{*} p<0.05,{ }^{* *} p<0.01$ versus controls.

idemia, hyperketosis, and decreased fasting levels of plasma NEFA (Fig. 4E). Together, these data indicate that overexpression of MBH TXNIP impairs the control of energy balance, nutrient partitioning, fuel utilization, and both hepatic and peripheral insulin sensitivity.

The impairment in glycemic control observed in $\mathrm{MBH}$ hTXNIP-expressing mice could result in part from a decrease in $\mathrm{MBH}$ insulin sensitivity in these mice. In fact, we found a $30 \%$ reduction in $\mathrm{MBH}$ Akt phosphorylation after an acute intra$\mathrm{MBH}$ insulin administration in hTXNIP-expressing mice compared with controls $(0.49 \pm 0.09$ vs $0.68 \pm 0.02$ in C247S hTXNIP and hTXNIP mice, respectively; $n=5, p<0.05$ ). Alternatively, glucose intolerance and insulin resistance after MBH TXNIP overexpression might be secondary to elevated body weight and adiposity. To address this possibility, we restricted $\mathrm{MBH}$ hTXNIP-expressing mice to achieve a body weight gain similar to that of C247S hTXNIP controls and compared their body composition, oral glucose, and insulin sensitivity to that of ad libitum fed hTXNIP-expressing mice. Baseline characteristics of these mice and mice from the original experiment are presented in Table 2. Restricted mice were leaner and displayed better glycemic control than ad libitum fed hTXNIP-expressing mice (Fig. 5). These results suggest that the higher body weight and adiposity of MBH TXNIP-overexpressing mice contribute to their impaired glycemic control. Consequently, we further investigated the mechanisms underlying increased fat deposition after overexpression of TXNIP in the MBH.

\section{MBH TXNIP overexpression and sympathetic control of} adipose tissue metabolism

A remarkable aspect of the metabolic phenotype obtained in mice overexpressing TXNIP in the $\mathrm{MBH}$ is their increased fat mass in the absence of an effect on food intake, suggesting alterations in the regulation of adipose tissue metabolism. Because sympathetic tone has been importantly implicated in adipose tissue metabolism, we tested the degree to which MBH TXNIP overexpression impaired sympathetic controls of adiposity. Intraperitoneal administration of the highly selective $\beta 3$ adrenergic receptor agonist (CL316243) activates brown fat thermogenesis and lipolysis, leading to an acute rise in circulating NEFA (Himms-Hagen et al., 1994; Grujic et al., 1997). In mice expressing hTXNIP in the $\mathrm{MBH}, \mathrm{CL} 316243$-induced NEFA release and brown fat thermogenesis were lower than in C247S hTXNIP controls (Fig. 6A). Cold exposure-induced sympathetic activation, as assessed by brown fat temperature change during a cold challenge, was also significantly decreased in hTXNIP-expressing mice (Fig. 6B). Additionally, fasting-induced lipolysis, known to be partly driven through sympathetic activation (Hücking et al., 2003), was blunted in hTXNIP-expressing mice compared with C247S hTXNIP controls, as measured by the fasting-induced increase in circulating NEFA (Fig. $4 E$ ), the fasting-induced weight loss, and the amount of food ingested during the refeeding phase after the fast (Fig. 6C). Together, these data indicate a decreased response to sympathetic stimuli in mice expressing hTXNIP in the MBH, which could be accounted for by decreased sympathetic tone and/or impaired adipocyte responses to sympathetic outflow. We further evaluated putative mechanisms underlying the impaired brown and white fat sympathetic responses in hTXNIP mice and found decreased brown fat expression of $\beta 3$ adrenergic receptor, peroxisome proliferator-activated receptor- $\gamma$ coactivator- $1 \alpha$ $(\mathrm{PGC} 1 \alpha)$, and uncoupling protein 1 (UCP1) in hTXNIP mice (Fig. 6D), consistent with the impaired temperature response reported above in different situations. In the epididymal adipose tissue, $\beta 3$ adrenergic receptor expression was downregulated, as well as the expression of $\beta 3$ adrenergic targets promoting lipolysis, such as HSL and perilipin (Fig. 6E), whereas caveolin and adipose triglyceride lipase (ATGL) expression were not affected (data not shown). Fasting-induced phosphorylation of epididymal fat AMP-activated protein kinase (AMPk) and HSL, each involved in the activation of lipolysis in response to increased sympathetic tone, were blunted in mice expressing hTXNIP in the $\mathrm{MBH}$ (Fig. $6 F$ ). Interestingly, higher expression levels of tumor necrosis factor (TNF) and F4/80 $(p<0.1)$ in epidydimal fat of MBH hTXNIP-expressing mice indicated increased adipose tissue inflammation in this group (Fig. 6G). Together, these results demonstrate that TXNIP overexpression in the MBH impairs thermogenesis and lipolysis through reductions in the response of brown and white fat cells to sympathetic output and promotes white adipose tissue inflammation.

\section{MBH TXNIP overexpression and $\mathrm{MBH}$ leptin sensitivity}

Because hypothalamic leptin signaling contributes to the central control of adiposity (Buettner et al., 2008) and regulates sympathetic tone (Nogueiras et al., 2007), we next assessed the effect of MBH TXNIP overexpression on hypothalamic leptin sensitivity. We found that expression of hTXNIP in the $\mathrm{MBH}$ impaired leptin-induced STAT3 phosphorylation (Fig. 7A). Consistent with impaired $\mathrm{MBH}$ leptin signaling in mice expressing hTXNIP, 
A $\square$ C247S TXNIP ם hTXNIP B

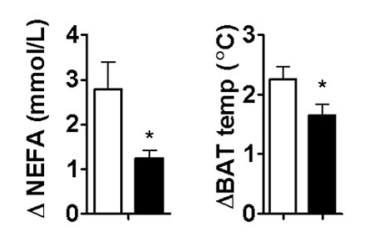

$\mathrm{E}$

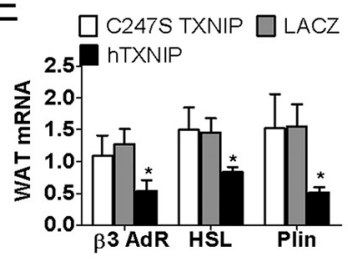

B

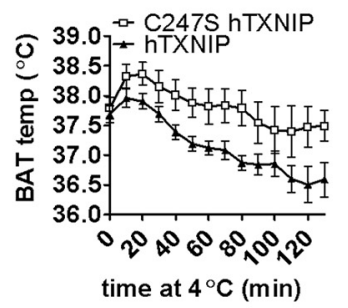

$\mathrm{F}$

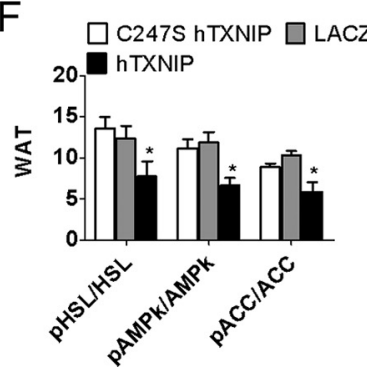

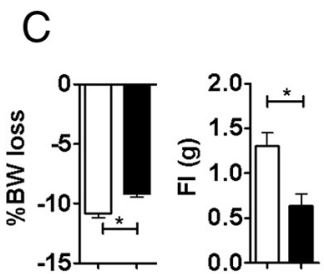

D $\quad$ C C247S TXNIP $\square L A C Z$ hTXNIP

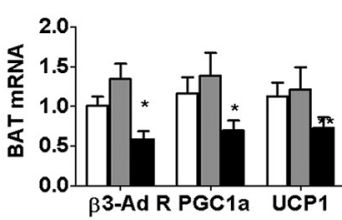

G

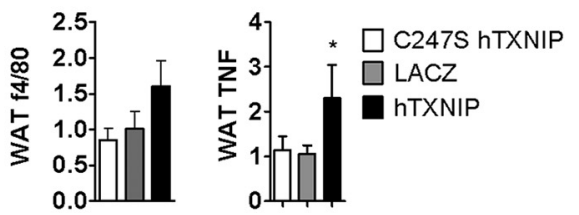

Figure 6. MBH TXNIP overexpression impairs sympathetic activity to white and brown fat and adipose tissue metabolism. Plasma NEFA and brown fat temperature changes after an intraperitoneal administration of $\mathrm{CL} 316243$, a $\beta 3$ receptor agonist $(\boldsymbol{A})$, cold sensitivity during a $2 \mathrm{~h}$ cold challenge at $4^{\circ} \mathrm{C}(\boldsymbol{B})$, body weight loss during a $24 \mathrm{~h}$ fast and food intake during the subsequent $4 \mathrm{~h}$ refeeding in mice injected with (247S or hTXNIP lentivirus into the MBH $(n=5)(\boldsymbol{C})$. Brown fat PGC1 $\alpha, \mathrm{UCP} 1$, and $\beta 3$ adrenergic receptor mRNA expression corrected to actin (D), visceral fat $\beta 3$ adrenergic receptor, HSL, and perilipin (Plin) mRNA expression corrected to actin (E), visceral fat AMPk $\alpha$ Thr172 phosphorylation and HSL Ser 563 phosphorylation $(\boldsymbol{F})$, and visceral fat F4/80 and TNF mRNA expression corrected to actin in fasted mice injected with C247S hTXNIP, LacZ, or hTXNIP lentivirus into the MBH (G). All data are means \pm SEM. ${ }^{*} p<0.05$, ${ }^{* *} p<0.01$ versus controls. BAT, Brown adipose tissue; WAT, white adipose tissue.

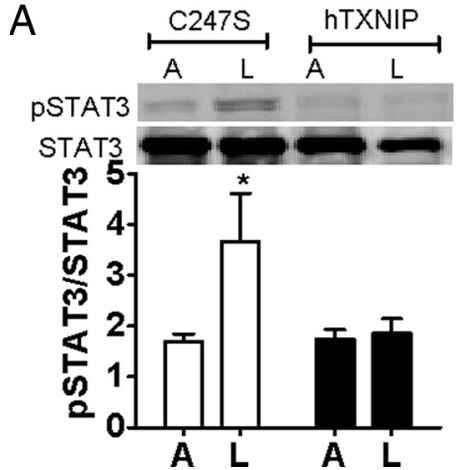

B

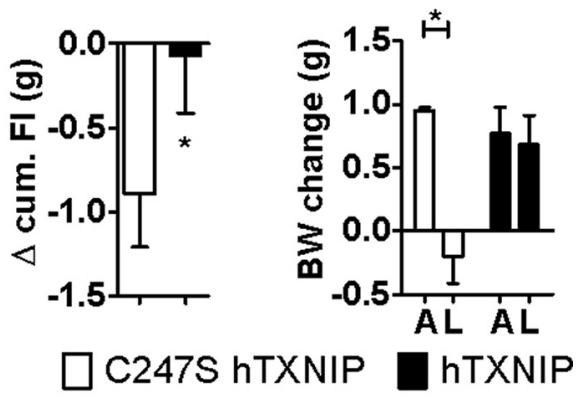

Figure 7. TXNIP overexpression in the MBH impairs MBH leptin action. $A$, Mediobasal hypothalamic leptin-induced STAT3 Y705 phosphorylation in mice expressing hTXNIP or C247S hTXNIP in the MBH $(n=5)$. B, Leptin-induced anorexia and body weight change in mice expressing hTXNIP or C247S hTXNIP in the MBH after an intra-MBH leptin (L; $150 \mathrm{ng})$ or aCSF (A) injection $(n=4)$. All data are means \pm SEM. ${ }^{*} p<0.05,{ }^{* *} p<0.01,{ }^{* * *} p<0.001$ versus controls.

intra-MBH leptin-induced anorexia and body weight loss were significantly blunted in this group compared with C247S hTXNIP controls (Fig. 7B). Thus, MBH TXNIP overexpression blunts the intracellular signaling, behavioral, and metabolic actions of MBH leptin.

\section{Downregulation of MBH TXNIP expression protects against the adverse metabolic effects of high-fat feeding}

Because overexpression of TXNIP in the MBH favored the development of obesity and insulin resistance in high-fat fed mice, we asked whether the converse was true and evaluated the ability of decreased MBH TXNIP expression to prevent diet-induced obesity and insulin resistance. We targeted the $\mathrm{MBH}$ with lentiviruses expressing an shRNA directed against TXNIP or a control shRNA in mice fed a high-fat diet. TXNIP shRNA lentivirus functional validity was confirmed in both N41 hypothalamic cells (data not shown) and $\mathrm{MBH}$ extracts from injected mice. $\mathrm{MBH}$ infection with the TXNIP shRNA led to a $40 \%$ decrease in TXNIP protein expression in the $\mathrm{MBH}$ (Fig. $8 \mathrm{~A}$ ) and induced a $50 \%$ increase in thioredoxin activity in the $\mathrm{MBH}(100.2 \pm 12.3$ vs $151.3 \pm 15.6$ expressed as percentage of controls in control and TXNIP shRNA mice, respectively; $p<0.05)$. This manipulation decreased the rate of body weight gain and fat deposition in mice expressing the TXNIP shRNA in the MBH compared with controls without significantly affecting energy intake (Fig. $8 \mathrm{~B}$ ). Oxygen consumption was significantly higher in the TXNIP shRNA group, without any change in respiratory quotient and locomotor activity (Fig. 8C). In addition, downregulation of MBH TXNIP expression improved glucose tolerance and the glucose response to an intraperitoneal insulin challenge (Fig. 8D,E). Euglycemic clamp experiments revealed that both a decrease in hepatic glucose production and an increase in peripheral glucose uptake under hyperinsulinemic conditions accounted for the improvement in glycemic control in this group compared with controls (Fig. $8 F$ ). These data indicate that downregulation of $\mathrm{MBH}$ TXNIP expression is an effective strategy to prevent diet-induced body weight gain, fat mass deposition, and insulin resistance.

\section{Discussion}

We have identified a novel contributor to hypothalamic nutrient sensing, TXNIP, selectively expressed in hypothalamic neuronal areas relevant to the control of energy homeostasis. We show that MBH TXNIP expression is nutritionally regulated, suppressed by anorexigenic signals (refeeding, insulin, and leptin), and activated during fasting in healthy lean mice. Importantly, in pathophysiological conditions of nutrient excess, TXNIP expression in the MBH is elevated, both acutely in the absence of obesity and 
diabetes, as well as in various mouse models of obesity and diabetes. Using a viral strategy to selectively overexpress TXNIP in the $\mathrm{MBH}$, we demonstrate that this process affects the $\mathrm{MBH}$ regulation of energy balance, substrate utilization, and glucose homeostasis, supporting a role for TXNIP induction in the MBH as a mechanism by which nutrient excess affect energy homeostasis in metabolic diseases. Last, using lentivectors to downregulate $\mathrm{MBH}$ TXNIP expression, we reveal a role for endogenous MBH TXNIP in the regulation of energy balance and glycemic control during diet-induced obesity.

The increased rate of body weight gain and fat mass resulting from TXNIP overexpression in the $\mathrm{MBH}$ are primarily explained by (1) a decrease in energy expenditure, as evidenced by decreased oxygen consumption, physical activity, and brown fat thermogenesis, and (2) a reduction in white fat lipolytic activity in the fasted state, in the absence of any effect on feeding behavior. The impaired mediobasal insulin and leptin sensitivity likely contribute to the impaired responses to sympathetic challenges we report in mice overexpressing TXNIP in the MBH. Interestingly, decreased $\beta 3$ adrenergic receptor expression in both brown and white fat accompanied decreased expression and/ or activity of cAMP-regulated targets, such as PGC1 $\alpha$ and its target UCP1 in the brown fat (Collins et al., 2004), and perilipin, HSL, and AMPk in the white fat (Haystead et al., 1990; Moule and Denton, 1998; Collins et al., 2004). Thus, decreased sympathetic outflow to both brown and white adipose tissue in mice overexpressing TXNIP in the MBH likely represents a major outcome accounting for their adipose tissue metabolic phenotype.

In addition to increasing fat mass, TXNIP overexpression in the $\mathrm{MBH}$ also impaired glucose tolerance, hepatic, and peripheral insulin sensitivity. Our data suggest that this effect on glycemic control is in part secondary to increased adipose tissue deposition and could be a consequence adipose tissue inflammation, as evidenced by increased epidydimal fat TNF expression. However, one cannot rule out a direct contribution of altered central nutrient-sensing pathways on the impaired glycemic control of MBH TXNIP-overexpressing mice. In particular, central leptin and insulin resistance, a consequence of $\mathrm{MBH}$ TXNIP overexpression, lead to diabetes (Bence et al., 2006; Ono et al., 2008) and likely contribute to the impaired glycemic control in mice overexpressing TXNIP in the MBH. Together, our data identify increased TXNIP expression in the $\mathrm{MBH}$ as a mechanism linking overnutrition to impairments in glycemic control and energy balance.

The present results reveal that all of the physiological outcomes directly related to glycemic control, in terms of glucose and insulin tolerance, glucose stimulated insulin secretion, the endogenous rate of glucose appearance, and the rate of glucose ${ }^{* *} p<0.01$ versus control.
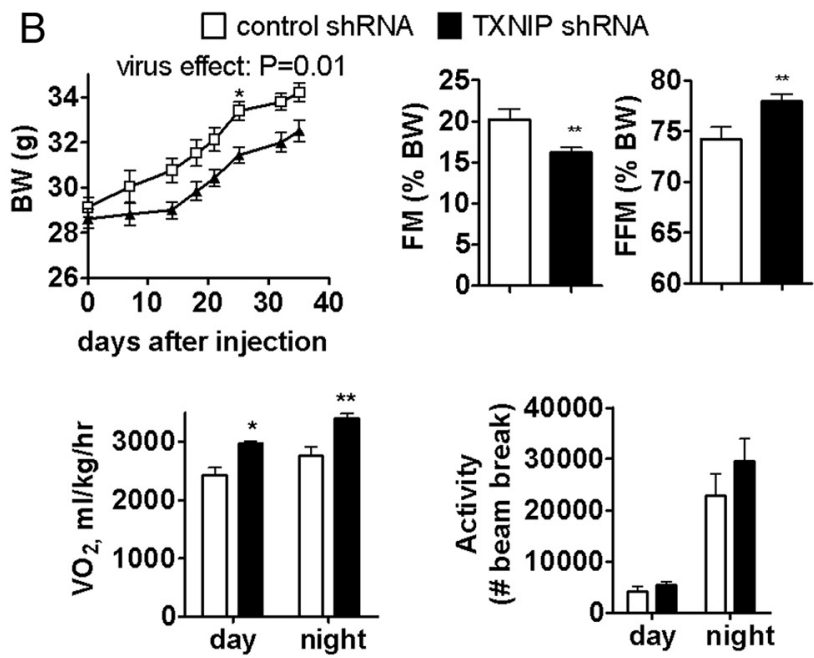

E
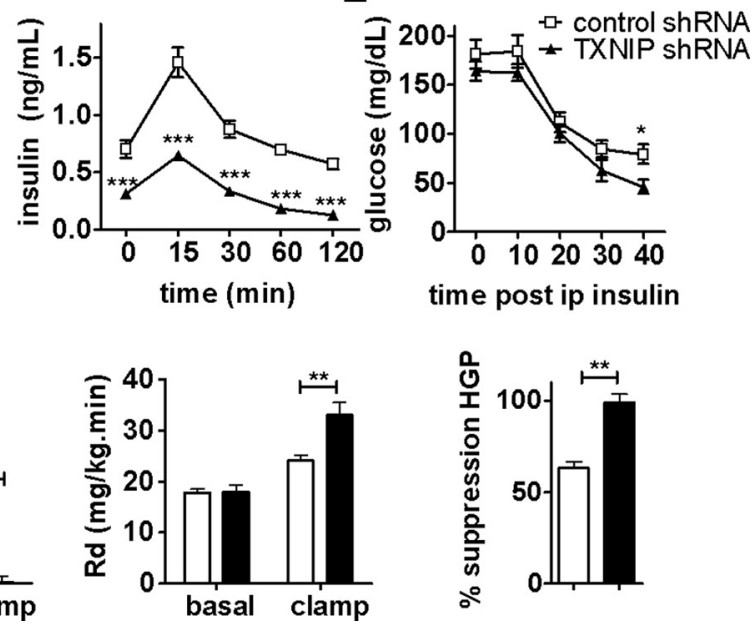

Figure 8. Downregulation of MBH TXNIP expression protects from diet-induced obesity and insulin resistance. TXNIP protein erssion corrected to actin in MBH of mice infected with TXNIP or control shRNA lentiviruses $(n=4)(A)$, body weight, fat mass plasma insulin during an oral glucose tolerance test $(\boldsymbol{D})$, blood glucose during an intraperitoneal insulin sensitivity test $(\boldsymbol{E})$, and 作, and percentage suppression of hepatic glucose production (HGP) during a euglycemic hyperinsulinemic clamp (D) in HFD-fed mice expressing TXNIP shRNA or a control shRNA in the MBH $(n=5-8)(\boldsymbol{F})$. All values are means \pm SEM. ${ }^{*} p<0.05$,

disposal during hyperinsulinemic-euglycemic clamps, are in opposite directions after the gain and loss of function of $\mathrm{MBH}$ TXNIP. However, because the MBH TXNIP knockdown strategy targets endogenous TXNIP, subsequent metabolic compensation after knockdown may mitigate against observing changes in behavioral effectors of energy balance such as locomotor activity, with a resulting lack of change in resting energy requirement.

The use of the C247S TXNIP mutant as a control demonstrates that the ability of TXNIP to bind thioredoxin is a requirement for its effect on energy homeostasis. Together with the bidirectional changes in thioredoxin activity obtained through $\mathrm{MBH}$ TXNIP gain and loss of function and the finding of an impaired intracellular redox state in mice overexpressing TXNIP in the $\mathrm{MBH}$, these data support the emerging view that the redox state within hypothalamic neurons is involved in the response to nutritional signals and the regulation of energy metabolism (Andrews et al., 2005; Leloup et al., 2006; Benani et al., 2007) and involve for the first time the thioredoxin redox buffer in this regulation. We show not only that it is involved in acute nutrient sensing but also in the long-term regulation of energy storage and 
utilization, an original finding. In summary, our work provides the first evidence in favor for a role of increased MBH TXNIP expression in obesity and diabetes as a mechanism linking nutrient excess to energy imbalance.

\section{References}

Andrews ZB, Diano S, Horvath TL (2005) Mitochondrial uncoupling proteins in the CNS: in support of function and survival. Nat Rev Neurosci $6: 829-840$.

Azzara AV, Sokolnicki JP, Schwartz GJ (2002) Central melanocortin receptor agonist reduces spontaneous and scheduled meal size but does not augment duodenal preload-induced feeding inhibition. Physiol Behav 77:411-416.

Benani A, Troy S, Carmona MC, Fioramonti X, Lorsignol A, Leloup C, Casteilla L, Pénicaud L (2007) Role for mitochondrial reactive oxygen species in brain lipid sensing: redox regulation of food intake. Diabetes $56: 152-160$

Bence KK, Delibegovic M, Xue B, Gorgun CZ, Hotamisligil GS, Neel BG, Kahn BB (2006) Neuronal PTP1B regulates body weight, adiposity and leptin action. Nat Med 12:917-924.

Blouet C, Ono H, Schwartz GJ (2008) Mediobasal hypothalamic p70 S6 kinase 1 modulates the control of energy homeostasis. Cell Metab $8: 459-467$.

Blouet C, Jo YH, Li X, Schwartz GJ (2009) Mediobasal hypothalamic leucine sensing regulates food intake through activation of a hypothalamusbrainstem circuit. J Neurosci 29:8302-8311.

Bodnar JS, Chatterjee A, Castellani LW, Ross DA, Ohmen J, Cavalcoli J, Wu C, Dains KM, Catanese J, Chu M, Sheth SS, Charugundla K, Demant P, West DB, de Jong P, Lusis AJ (2002) Positional cloning of the combined hyperlipidemia gene Hyplip1. Nat Genet 30:110-116.

Buettner C, Muse ED, Cheng A, Chen L, Scherer T, Pocai A, Su K, Cheng B, Li X, Harvey-White J, Schwartz GJ, Kunos G, Rossetti L, Buettner C (2008) Leptin controls adipose tissue lipogenesis via central, STAT3independent mechanisms. Nat Med 14:667-675.

Chen J, Saxena G, Mungrue IN, Lusis AJ, Shalev A (2008) Thioredoxininteracting protein: a critical link between glucose toxicity and beta-cell apoptosis. Diabetes 57:938 -944.

Collins S, Cao W, Robidoux J (2004) Learning new tricks from old dogs: beta-adrenergic receptors teach new lessons on firing up adipose tissue metabolism. Mol Endocrinol 18:2123-2131.

Grujic D, Susulic VS, Harper ME, Himms-Hagen J, Cunningham BA, Corkey BE, Lowell BB (1997) Beta3-adrenergic receptors on white and brown adipocytes mediate beta3-selective agonist-induced effects on energy expenditure, insulin secretion, and food intake. A study using transgenic and gene knockout mice. J Biol Chem 272:17686-17693.

Haystead TA, Moore F, Cohen P, Hardie DG (1990) Roles of the AMPactivated and cyclic-AMP-dependent protein kinases in the adrenalineinduced inactivation of acetyl-CoA carboxylase in rat adipocytes. Eur J Biochem 187:199-205.

Himms-Hagen J, Cui J, Danforth E Jr, Taatjes DJ, Lang SS, Waters BL, Claus TH (1994) Effect of CL-316,243, a thermogenic beta 3-agonist, on energy balance and brown and white adipose tissues in rats. Am J Physiol 266:R1371-R1382.

Holmgren A, Björnstedt M (1995) Thioredoxin and thioredoxin reductase. Methods Enzymol 252:199-208.

Hücking K, Hamilton-Wessler M, Ellmerer M, Bergman RN (2003) Burst- like control of lipolysis by the sympathetic nervous system in vivo. J Clin Invest 111:257-264.

Hui ST, Andres AM, Miller AK, Spann NJ, Potter DW, Post NM, Chen AZ, Sachithanantham S, Jung DY, Kim JK, Davis RA (2008) Txnip balances metabolic and growth signaling via PTEN disulfide reduction. Proc Natl Acad Sci U S A 105:3921-3926.

Hui TY, Sheth SS, Diffley JM, Potter DW, Lusis AJ, Attie AD, Davis RA (2004) Mice lacking thioredoxin-interacting protein provide evidence linking cellular redox state to appropriate response to nutritional signals. J Biol Chem 279:24387-24393.

Leloup C, Magnan C, Benani A, Bonnet E, Alquier T, Offer G, Carriere A, Périquet A, Fernandez Y, Ktorza A, Casteilla L, Pénicaud L (2006) Mitochondrial reactive oxygen species are required for hypothalamic glucose sensing. Diabetes 55:2084-2090.

Lippoldt A, Padilla CA, Gerst H, Andbjer B, Richter E, Holmgren A, Fuxe K (1995) Localization of thioredoxin in the rat brain and functional implications. J Neurosci 15:6747-6756.

Morton GJ, Cummings DE, Baskin DG, Barsh GS, Schwartz MW (2006) Central nervous system control of food intake and body weight. Nature 443:289-295.

Moule SK, Denton RM (1998) The activation of p38 MAPK by the betaadrenergic agonist isoproterenol in rat epididymal fat cells. FEBS Lett 439:287-290.

Nishiyama A, Matsui M, Iwata S, Hirota K, Masutani H, Nakamura H, Takagi Y, Sono H, Gon Y, Yodoi J (1999) Identification of thioredoxin-binding protein-2/vitamin $\mathrm{D}(3)$ up-regulated protein 1 as a negative regulator of thioredoxin function and expression. J Biol Chem 274:21645-21650.

Nogueiras R, Wiedmer P, Perez-Tilve D, Veyrat-Durebex C, Keogh JM, Sutton GM, Pfluger PT, Castaneda TR, Neschen S, Hofmann SM, Howles PN, Morgan DA, Benoit SC, Szanto I, Schrott B, Schürmann A, Joost HG, Hammond C, Hui DY, Woods SC, et al. (2007) The central melanocortin system directly controls peripheral lipid metabolism. J Clin Invest 117:3475-3488.

Ono H, Pocai A, Wang Y, Sakoda H, Asano T, Backer JM, Schwartz GJ, Rossetti L (2008) Activation of hypothalamic S6 kinase mediates dietinduced hepatic insulin resistance in rats. J Clin Invest 118:2959-2968.

Parton LE, Ye CP, Coppari R, Enriori PJ, Choi B, Zhang CY, Xu C, Vianna CR, Balthasar N, Lee CE, Elmquist JK, Cowley MA, Lowell BB (2007) Glucose sensing by POMC neurons regulates glucose homeostasis and is impaired in obesity. Nature 449:228-232.

Patwari P, Higgins LJ, Chutkow WA, Yoshioka J, Lee RT (2006) The interaction of thioredoxin with Txnip. Evidence for formation of a mixed disulfide by disulfide exchange. J Biol Chem 281:21884-21891.

Paxinos G, Franklin KBJ (2001) The mouse brain in stereotaxic coordinates, Ed 2. New York: Academic.

Ross RA, Rossetti L, Lam TK, Schwartz GJ (2010) Differential effects of hypothalamic long-chain fatty acid infusions on suppression of hepatic glucose production. Am J Physiol Endocrinol Metab 299:E633-E639.

Sheth SS, Castellani LW, Chari S, Wagg C, Thipphavong CK, Bodnar JS, Tontonoz P, Attie AD, Lopaschuk GD, Lusis AJ (2005) Thioredoxininteracting protein deficiency disrupts the fasting-feeding metabolic transition. J Lipid Res 46:123-134.

Steele R, Wall JS, De Bodo RC, Altszuler N (1956) Measurement of size and turnover rate of body glucose pool by the isotope dilution method. Am J Physiol 187:15-24. 